Erratum

\title{
Erratum to "Composite Fault Diagnosis for Rotating Machinery of Large Units Based on Evidence Theory and Multi-Information Fusion"
}

\author{
Naiquan Su $\mathbb{D}^{1,2}{ }^{1,2}$ Xiao Li, ${ }^{1}$ Qinghua Zhang, ${ }^{2}$ and Zhiqiang $\mathrm{Huo}^{3}$ \\ ${ }^{1}$ School of Electromechanical Engineering, Guangdong University of Technology, Guangzhou 510006, China \\ ${ }^{2}$ Guangdong Province Key Laboratory of Petrochemical Equipment Fault Diagnosis, Maoming 525000, China \\ ${ }^{3}$ School of Engineering, University of Lincoln, Lincoln LN6 7TS, UK \\ Correspondence should be addressed to Naiquan Su; 534306286@qq.com
}

Received 20 April 2020; Accepted 22 June 2020; Published 23 October 2020

Copyright (C) 2020 Naiquan Su et al. This is an open access article distributed under the Creative Commons Attribution License, which permits unrestricted use, distribution, and reproduction in any medium, provided the original work is properly cited.

In the article titled "Composite Fault Diagnosis for Rotating Machinery of Large Units Based on Evidence Theory and Multi-Information Fusion" [1], the name of the first author was given incorrectly as Naiquang Su. It should have been written as Naiquan Su. The updated authors' list is shown above.

\section{References}

[1] N. Su, X. Li, Q. Zhang, and Z. Huo, "Composite fault diagnosis for rotating machinery of large units based on evidence theory and multi-information fusion," Shock and Vibration, vol. 2019, Article ID 1982317, 12 pages, 2019. 